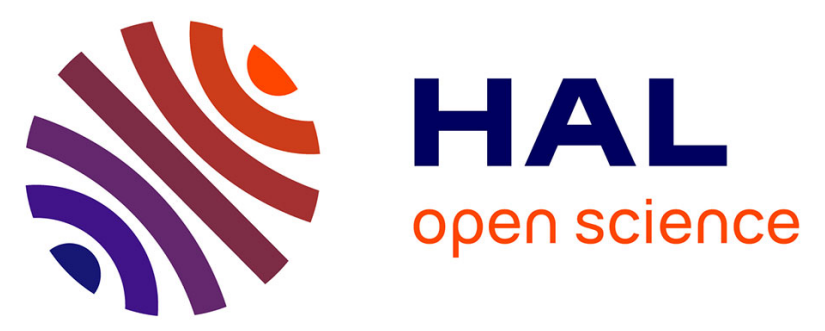

\title{
Tourism in protected areas can threaten wild populations: from individual response to population viability of the chough Pyrrhocorax pyrrhocorax
}

Christian Kerbiriou, Isabelle Le Viol, Alexandre Robert, Emmanuelle Porcher, Françoise Gourmelon, Romain Julliard

\section{- To cite this version:}

Christian Kerbiriou, Isabelle Le Viol, Alexandre Robert, Emmanuelle Porcher, Françoise Gourmelon, et al.. Tourism in protected areas can threaten wild populations: from individual response to population viability of the chough Pyrrhocorax pyrrhocorax. Journal of Applied Ecology, 2009, 46 (46), pp.657-665. 10.1111/j.1365-2664.2009.01646.x . hal-00385031

\section{HAL Id: hal-00385031 \\ https://hal.science/hal-00385031}

Submitted on 19 Aug 2019

HAL is a multi-disciplinary open access archive for the deposit and dissemination of scientific research documents, whether they are published or not. The documents may come from teaching and research institutions in France or abroad, or from public or private research centers.
L'archive ouverte pluridisciplinaire HAL, est destinée au dépôt et à la diffusion de documents scientifiques de niveau recherche, publiés ou non, émanant des établissements d'enseignement et de recherche français ou étrangers, des laboratoires publics ou privés. 


\title{
Tourism in protected areas can threaten wild populations: from individual response to population viability of the chough Pyrrhocorax pyrrhocorax
}

\author{
Christian Kerbiriou ${ }^{1 *}$, Isabelle Le Viol ${ }^{1}$, Alexandre Robert ${ }^{1}$, Emmanuelle Porcher ${ }^{1}$, \\ Françoise Gourmelon ${ }^{2}$ and Romain Julliard ${ }^{1}$ \\ ${ }^{1}$ Muséum National d'Histoire Naturelle CERSP UMR 7204 MNHN-CNRS-UPMC, 55 rue Buffon, 75005 Paris, France; \\ and ${ }^{2}$ CNRS - UMR 6554, GeoMer - Institut Universitaire Européen de la Mer, 29280 Plouzané France
}

\begin{abstract}
Summary
1. Many protected areas are now faced with increasing pressure from visitors and tourism development. There is thus an urgent need for conservation biologists to evaluate the full impact of human disturbance not only on individual responses, but also on the viability of protected populations, so that relevant management measures can be proposed.

2. We studied the impact of tourism on the rare and endangered chough Pyrrhocorax pyrrhocorax on a protected French island to assess the relationship between visitor pressure, bird individual behaviour and fitness, and population viability. During 8 years, we monitored foraging behaviour and estimated monthly juvenile survival using mark-recapture data. Population viability was examined under different tourism scenarios, using a stochastic individual-based model that incorporated the impact of visitor numbers on juvenile survival.

3. In summer, the foraging probability of choughs was negatively correlated with the number of visitors. As a result, the time allocated to foraging during peak tourist season, adjusted to day length and prey availability, was $50 \%$ lower than expected.

4. Juvenile survival rates were lowest in August, the peak tourist season, and varied significantly across years. August survival rate and therefore annual survival were negatively correlated with the number of visitors on the island in August and, except for a minor negative effect of rainfall, were not influenced by other environmental variables.

5. Stochastic simulations predicted a low probability of extinction of the protected population if the number of visitors remains constant in the future. However, short-term viability would be dramatically reduced if the current rate of increase in visitor numbers is maintained.

6. Synthesis and applications. We show that a relatively minor human-induced disturbance (e.g. scaring individuals away) has dramatic effects on population viability in a protected area, even when breeding individuals are not directly affected. This suggests that the full impact of tourism in protected areas may be overlooked, and has direct consequences for the assessment of sustainable levels of human disturbance and the design of quantitative management options compatible with tourist activities in protected areas. We specifically emphasize the need for more integrative approaches combining research at individual and population levels.
\end{abstract}

Key words: tourism disturbance, population viability analysis, individual-based-model, sensitivity of growth rate, Biosphere Reserve, ecological compensation, visitor access, recreation, Ouessant Island

\section{Introduction}

Protected areas, which now cover more than $11 \%$ of the Earth's terrestrial surface (Rodrigues et al. 2004), play a crucial role in tourism and receive an ever-increasing number of visitors

*Correspondence author: E-mail: kerbiriou@mnhn.fr
(Buckley 2003). Many protected areas were primarily designed to conserve species and habitats without consideration for visitor access (Boo 1990), which may result in significant wildlife disturbance and/or habitat degradation by visitors (Kelly, Pickering \& Buckley 2002). Numerous studies have documented a negative impact of tourism on individual responses of disturbed animals, including behavioural changes (avoidance behaviour, 
Belanger \& Bedard 1989; Beale \& Monaghan 2004, Holm \& Laursen 2009; reduction in feeding time, Duchesne, Cote \& Barette 2000 or resting time, King \& Heinen 2004; changes in social structure, Saltz et al. 2002) and physiological responses (e.g. modification of heart rate, McArthur, Geist \& Johnston 1982, Thiel et al. 2008). Such information could be used by conservation biologists and/or managers to evaluate sustainable levels of disturbance or propose landscape management measures to ensure the viability of protected populations (Liley \& Sutherland 2007; Mallord et al. 2007).

However, most studies of the impact of tourism have focused on individual response, with little consideration for populationlevel response (but see Carney \& Sydeman 1999, Nisbet 2000, Patthey et al.2008), so that studies concluding that tourism has negative effects on population viability are being questioned (Hill et al. 1997, Gill, Norris \& Sutherland 2001). To demonstrate an effect of individual responses of disturbed animals on the dynamics and viability of populations, one should show that human disturbance reduces individual fitness, which, in turn, influences population dynamics and viability when summed over the entire population. However, the mean daily duration of disturbance of individuals is generally short (e.g. Hulbert 1990) and can be partly compensated for by behavioural changes (Riddington et al. 1996). Furthermore, human disturbance is generally confined to a small fraction of a given protected area, so that relatively few individuals of the population of concern are affected. Consequently, previous studies have generally failed to detect a decrease in fecundity or survivorship with increasing human disturbance (King \& Heinen 2004).

In this study, we combine long-term population monitoring and modelling to document the impact of tourism on individual response and population viability of the red-billed chough Pyrrhocorax pyrrhocorax Linnaeus (hereafter name chough), a rare and declining bird species in Europe, and to propose management measures to protect the population in the long term. The study population breeds on Ouessant Island in Western France, a highly protected area where the number of visitors has increased considerably in recent years, so that tourism has become the main source of income for the islanders. We demonstrate that tourism-related disturbance affects the viability of the Ouessant chough population by characterizing changes in individual behaviour induced by the presence of visitors and examining the relationship between individual response and fitness. We used monthly juvenile survival, estimated with colour-mark resighting data, as a proxy for individual fitness. These data were then incorporated into a population dynamics model to project the influence of human disturbance on present and future population viability under different scenarios of tourism development.

\section{Materials and methods}

\section{STUDY SITE}

Ouessant is a small island (1541 ha) located $20 \mathrm{~km}$ west off the western coast of Brittany, France $\left(48^{\circ} 28^{\prime} \mathrm{N}, 5^{\circ} 5^{\prime} \mathrm{W}\right)$. Due to the presence of rare species, high biological diversity and an exceptionally preserved coastal ecosystem, it is highly protected (Supporting Information, Fig. S1). During the last 50 years, the number of visitors on Ouessant has increased dramatically, due to a combination of (i) a general increased desire to explore natural environments, and (ii) the liberalization of passenger transport services in 1990 , which resulted in increased ferry passenger carrying capacity (Levrel et al., in press). The annual number of ferry passengers increased from 5000 in 1950 to 150000 in 2005, with a constant annual increase of c. 2500 passengers during the last 20 years and no signs of levelling-off in the near future (Levrel et al. in press). High season runs from the second week of July to the end of August, with a peak in August (48\% of annual visits). Tourism is currently the main source of income on the island. Most visitors take a 1-day excursion to the island; they are mostly interested in the spectacular coastline scenery, which they discover by following paths around the island, and are generally not aware of the presence of endangered species and habitats (C. Kerbiriou unpublished data).

\section{FOCAL SPECIES}

The chough has a scattered distribution, resulting from specific ecological requirements, (i.e. suitable nesting sites: shallow caves in cliffs) and foraging areas (short grassland with low cover, Blanco, Tella \& Torre 1998). During the 19th and 20th centuries, the distribution and population sizes of the chough in Europe have declined drastically (Kerbiriou 2001; Burfield \& Bommel 2004) and the species is now listed in Annex 1 of the European Union Directive on the Conservation of Wild Birds (79/409/EEC). This strong decrease is thought to result from changes in agricultural practices, notably abandonment of grasslands that used to provide suitable foraging habitats for choughs (Kerbiriou 2001). The western French population of chough is now confined to very few localities in Brittany and seems to have stabilized at a small size (39-55 pairs in 2002, Kerbiriou et al. 2005). The population is limited to coastal sites where short grassland habitat above cliffs is maintained by marine physical factors, such as wind and salt spray, i.e. precisely where visitors like to walk. In particular, choughs are never seen in inland agricultural grasslands, which tend to be undergrazed and too tall for choughs to forage (Kerbiriou et al. 2006a). Birds are typically distributed around the island coastline in pairs and in a few small cohesive flocks with immature birds.

\section{DATA COLLECTION AND ANALYSIS}

We monitored the chough population of Ouessant between 1993 and 2005 , focusing on the potential impact of tourism on chough behaviour and demography.

\section{Flush distance}

Flush distance was defined as the distance at which a foraging bird or flock will fly off when approached by a person or group of persons. Flush distance was estimated to the nearest $10 \mathrm{~m}$ using take-offs caused unintentionally by visitors walking towards the choughs $(n=103)$ or triggered by a member of the research team to increase sample size $(n=63)$. We explored the effects of flock size, presence of dependent fledglings, visitor group size, type of disturbance (unintentional vs. intentional) and season on the flush distance using a linear model and analysis of variance. 


\section{Seasonal and daily variation in the spatial distribution of choughs}

To study feeding habitat choice, we first examined the spatial distribution of choughs in relation to feeding habitat availability. We have shown previously that choughs avoid inland pastures and feed almost exclusively in very short swards $(<5 \mathrm{~cm}$, Kerbiriou et al. 2006a) found exclusively on the coastline. Hence, we surveyed the coastline only, which was divided into 123 squares measuring $250 \times 250 \mathrm{~m}$ (see Supporting Information, Appendix S1). During the summer in 1993 and 1994, and all year round between 1995 and 2001, each square was routinely surveyed for 10 to $30 \mathrm{~min}$ by the same observer at least once a month, yielding a total of ca. 80000 data points. For each observation, we recorded date, time and number of choughs observed; when choughs were present $(n=$ 8273), we also recorded the behaviour of each individual on first contact (foraging, resting or flying). The reproductive season of the chough (mid-March to early July) was excluded because (i) the bird distribution is controlled mainly by territorial defence (Kerbiriou et al. 2006a), and (ii) the number of visitors is intermediate and concentrated on a few specific dates (public holidays).

Short grasslands $(<5 \mathrm{~cm})$ and paths were mapped from field observations and aerial photographs (IGN 2002), and the map was implemented in a GIS (ARCGIS9 1/ESRI). We also measured the area of feeding habitat in each $250 \times 250 \mathrm{~m}$ square. We studied the spatial distribution of birds in relation to their feeding habitat (i) in winter, when visitors are virtually absent, and (ii) in summer, during the peak tourist season, by using a Poisson linear mixed model ( $\mathrm{R}$, lme4 package), where the number of choughs observed in a square was a function of the area of feeding habitat in this square $\left(\mathrm{m}^{2}\right)$, time of the day, a random square effect, and the average number of choughs in adjacent squares, to account for possible spatial autocorrelation.

\section{Impact of tourism on foraging behaviour}

Simultaneously with bird counts, the number of visitors was recorded on areas about 10 times larger than those defined for chough observation, because visitors tend to move around more than foraging birds. These larger areas (hereafter 'visitor zones') are a combination of squares used for chough observation and correspond to the main points of interest on Ouessant (see Supporting Information, Fig. S1 and Kerbiriou et al. 2008).

As for each observation we have information of all bird behaviour, we used the proportion of foraging individuals as a proxy for foraging time, which, we assume, carries information on food intake. To study the impact of tourism on foraging, we first examined annual variation in foraging time and compared the peak tourist season (August) to neighbouring months (see Supporting Information, Appendix S2 for a description of how confounding effects of day length and prey availability were removed).

Secondly, we assessed the correlation between the number of choughs observed foraging and the number of visitors using a Poisson linear mixed model (R, lme4 package), as well as a Generalized Additive Model (GAM, Hastie \& Tibshirani 1990, R package mgcv), because we expected a non-linear relationship due, for example, to threshold behavioural responses. Spatial autocorrelation was accounted for as described above.

Finally, we quantified the spatio-temporal decrease in available feeding habitat generated by the presence of visitors. To this end, we used the observed relationship between number of foraging choughs and number of tourists to assess the threshold number of visitors above which birds stop foraging in a given visitor zone. By combining this information and the observed daily number of visitors on the island, we estimated the total area of feeding habitat available for each hour of a day. For each day, this value was summed over all hours of daylight and compared to the total area of feeding habitat to generate a daily spatio-temporal decrease in feeding habitat.

\section{Estimates of juvenile survival rates}

Because the peak tourist season on Ouessant occurs simultaneously with the fledging period of the chough, we expected a strong impact of the presence of visitors on chough juvenile survival. Chough breeding success was monitored thoroughly from 1998 to 2005 (on average 12 breeding pairs each year). All accessible juveniles were colour-ringed a few days before fledging ( $n=122$, representing $72 \%$ of fledglings observed between 1998 and 2005). Juvenile survival was estimated through resighting of marked individuals $(n=2972$ records), via a square-by-square survey similar to that used to collect behavioural data. Resighting data between Ouessant and the mainland coast (not shown) suggest that dispersal outside Ouessant is possible but occurs rarely (as in Reid et al. 2004) and is unlikely to remain undetected.

Monthly survival was estimated each year between June and December. The date of disappearance of a given individual was estimated accurately, thanks to very high resighting rates, that is, all living individuals were seen at least once every 30 days (between 1998 and 2003) or 60 days (in 2004-2005). We estimated monthly juvenile survival using the Cormack-Jolly-Seber (CJS) model (Pollock et al. 1995) implemented in program MARK (White \& Burnham 1999). The following covariates were included in the survival analysis: (i) total number of visitors in August (ranging from 27431 to 42243 between 1998 and 2005, data from ferry companies and office of tourism), to test the impact of tourism on juvenile survival; (ii) annual productivity (number of fledglings on Ouessant, ranging from 15 to 32) to assess a possible year quality effect (as in Reid et al. 2003a); (iii3) climatic data (monthly rainfall, temperature and number of sunny days; data from the Ouessant meteorological station/Météo France), to investigate whether monthly survival depended on environmental conditions. For details on the goodness of fit, the model selection, and the design matrix see Supporting Information, Table S2.2.

\section{Viability of the Ouessant chough population}

We assessed the effects of tourism on chough population viability using two types of population models. First, a deterministic matrix model (computer program ULM; Ferrière et al. 1996) was developed to examine population equilibrium and sensitivity of the population growth rate to demographic parameters (Zambrano et al. 2007). Parameter values were obtained from this or previous experimental studies (see Supporting Information, Fig. S2.3).

Secondly, to examine the joint effects of population regulation (limited number of nesting sites, as suggested by a census of available nesting areas, Kerbiriou et al. 2006b), temporal and environmental variation (tourism), as well as demographic stochasticity, we developed a stochastic two-sex individual-based population model (IBM). The IBM allowed a complete description of sex, age, and reproductive status (nesting versus non nesting) of all individuals (see Supporting Information, Fig. S2.3). Because tourism was shown to strongly affect August juvenile survival (see Results), we modelled the expected August juvenile survival in year $t$ as a function of the number of visitors in August (divided by 1000) the same year, using 
results from the most parsimonious model of capture-recapture of monthly juvenile survival. The relationship between August juvenile survival in year $t, s_{a, t}$, and number of visitors in August, $x_{t}$, takes the form: $s_{a, t}=e^{a x_{t}+b} /\left(1+e^{a x_{t}+b}\right)$. For the sake of simplicity, we did not incorporate the effect of weather on juvenile survival, which was small compared to the effect of visitor number. Therefore, $a$ and $b$ coefficients used in the above equation were estimates from the survival model including the effect of tourism only (see model selection presented in Supporting Information, Table S3.3). The values of these coefficients were $\mathrm{a}=0 \cdot 29(\mathrm{SE}=0 \cdot 073)$ and $b=10 \cdot 11$ $(\mathrm{SE}=2 \cdot 56)$. The average juvenile survival rate in year $t$ was thus $s_{0}(t)=s_{r} s_{a, t}$, where $s_{r}=0.509$ is the juvenile survival rate for the rest of the year (constant across years). Different scenarios for the variation of number of tourist $\left(x_{t}\right)$ through time were investigated to extrapolate the effects of tourism on population dynamics and viability. Scenario A: constant number of visitors; $x_{t}$ was set to the average value estimated over the 8 years study period (32 150); Scenario B: stochastic annual variation in visitor numbers, no deterministic increase; $x_{t}$ was varied stochastically across years, by sampling from a Normal distribution with mean 32150 and standard deviation 5350 (estimated from data over the study period); Scenario $\mathrm{C}$ : deterministic increase in visitor number; $x_{t}$ was a linear function of time, $x_{t}=0 \cdot 7 t+32150$ (Supporting information, Fig. S1 and Levrel et al. in press), estimated from the observed trend in visitor numbers in Ouessant over the last 20 years; Scenario D: deterministic increase and stochastic variation in visitor numbers; $x_{t}^{\prime}$ was drawn from a normal distribution with mean $x_{t}=0.7 t+32150$ and standard deviation 5350. In each case, $N_{0}$ individuals (the current population size, $n=55$ ) were initially present in the population.

\section{Results}

\section{FLUSH DISTANCE}

Flush distance was significantly increased by the presence of dependent juveniles in the flock $\left(F_{2,156}=59.60, P<0.0001\right.$; average flush distance $=147 \pm 23$ vs. $75 \pm 9 \mathrm{~m}$ for flocks with and without juveniles, respectively). Flush distance was not affected by visitor number $\left(F_{1,155}=0.69, P=0 \cdot 41\right)$, type of disturbance (unintentional vs. intentional, $F_{1,155}=0 \cdot 01$, $P=0 \cdot 91)$ or flock size $\left(F_{1,155}=2 \cdot 557, P=0 \cdot 11\right)$. By combining the average flush distance and the spatial distribution of paths on the coastline, we estimated that $97 \%$ of the main feeding habitat of the chough was potentially affected by human disturbance.

\section{SPATIAL DISTRIBUTION OF CHOUGHS AND VISITORS}

In winter, the spatial distribution of chough flocks was positively correlated with the amount of feeding habitat throughout the day, whereas in summer this correlation was significant in early morning or late afternoon only (Table 1 and Supporting Information, Table S3.1). In summer at midday when visitors were present, the largest number of choughs was observed on an inaccessible islet with small areas of feeding habitat. In summer afternoons, visitors were found almost everywhere, but highest densities occurred on the western part of the island, i.e. in places where choughs had disappeared (Supporting information, Table S3.1).
Table 1. Within-day correlation between the spatial distribution of choughs and feeding habitat areas in winter and summer. Linear mixed model with additive effect of average chough in neighbouring square, habitat areas and a random effect of square surveyed

\begin{tabular}{|c|c|c|c|c|}
\hline \multirow[b]{2}{*}{ Time } & \multicolumn{2}{|c|}{$\begin{array}{l}\text { Winter correlation } \\
\text { between chough } \\
\text { and habitat }\end{array}$} & \multicolumn{2}{|c|}{$\begin{array}{l}\text { Summer correlation } \\
\text { between chough } \\
\text { and habitat }\end{array}$} \\
\hline & Estimate & $P$ & Estimate & $P$ \\
\hline 8 & $6 \cdot 70$ & $* * *$ & $1 \cdot 81$ & ns \\
\hline 9 & 3.98 & $* * *$ & $2 \cdot 35$ & $* * *$ \\
\hline 10 & $3 \cdot 43$ & $* * *$ & $2 \cdot 49$ & $* * *$ \\
\hline 11 & $2 \cdot 38$ & $* * *$ & $1 \cdot 16$ & $\mathrm{~ns}$ \\
\hline 12 & $2 \cdot 28$ & $* * *$ & 0.02 & ns \\
\hline 13 & $2 \cdot 20$ & $* * *$ & $-0 \cdot 19$ & $\mathrm{~ns}$ \\
\hline 14 & $2 \cdot 40$ & $* * *$ & -0.33 & ns \\
\hline 15 & $1 \cdot 86$ & $* * *$ & -0.46 & ns \\
\hline 16 & $2 \cdot 15$ & $* * *$ & $0 \cdot 71$ & $\mathrm{~ns}$ \\
\hline 17 & $1 \cdot 77$ & $* * *$ & $0 \cdot 49$ & $\mathrm{~ns}$ \\
\hline 18 & $3 \cdot 17$ & $* * *$ & $1 \cdot 39$ & $\mathrm{~ns}$ \\
\hline 19 & 1.91 & $* * *$ & $1 \cdot 88$ & $* *$ \\
\hline 20 & $0 \cdot 32$ & ns & $3 \cdot 00$ & $*$ \\
\hline
\end{tabular}

ns, $P>0 \cdot 05 ; * P<0 \cdot 05 ; * * P<0 \cdot 001 ; * * * P<0 \cdot 0001$.

\section{FORAGING BEHAVIOUR}

We observed a large variation in the frequency of foraging behaviour, a lot of which was attributable to tourism disturbance. Two observations support a negative impact of visitors on foraging time.

First, comparisons in space or time showed that undisturbed choughs systematically forage (hence feed) for longer time periods than individuals that are disturbed by visitors. Temporally, this was true when comparing different hours within a day or different months within a year. In winter, on average $90 \%$ of individuals were observed foraging in a given flock, with little variation throughout the day (Fig. 1). In contrast, in summer, there was a large within-day variation in the frequency of foraging individuals, which was high $(85 \%)$ in the morning and evening, but much lower $(33 \%)$ in the middle of the day, during peak visitor hours; the remaining $67 \%$ individuals were seen in flight or resting (Fig. 1). In addition, a comparison of consecutive months, minimizing the variation of confounding factors, showed that only $58 \%$ of observed choughs were foraging in August $(n=7063)$ vs. $77 \%$ in June $(n=4770), 86 \%$ in September $(n=4874)$ and $91 \%$ in October $(n=3289)$. Even when the confounding effects of day length and prey availability were removed, the time allocated to foraging in August was still 56\% lower than in June, 43\% lower than in September and 37\% lower than in October. Spatially, we compared foraging time during summer afternoons on the main island vs. on a small inaccessible islet on which most individuals were observed (Supporting Information, Fig. S2): $65 \%$ of observed choughs were foraging on the undisturbed islet vs. $33 \%$ on the main island.

Secondly, when controlling for within-day variation, the frequency of observed foraging behaviour in summer was negatively correlated with visitor number $\left(\right.$ GLM $\chi^{2}=1582 \cdot 4$, d.f. $=1, P<0.0001$ and Fig. 2). This result was true even 
Fig. 1. Daily variation in the average observed proportion of foraging choughs (solid line: $\mathbf{\square}$, winter, $n=2183 ; \square$, summer, $n=1445)$ and average number of visitors per zone (dotted line: $\bullet$, winter, $n=2708$; $\bigcirc$, summer, $n=2151)$.
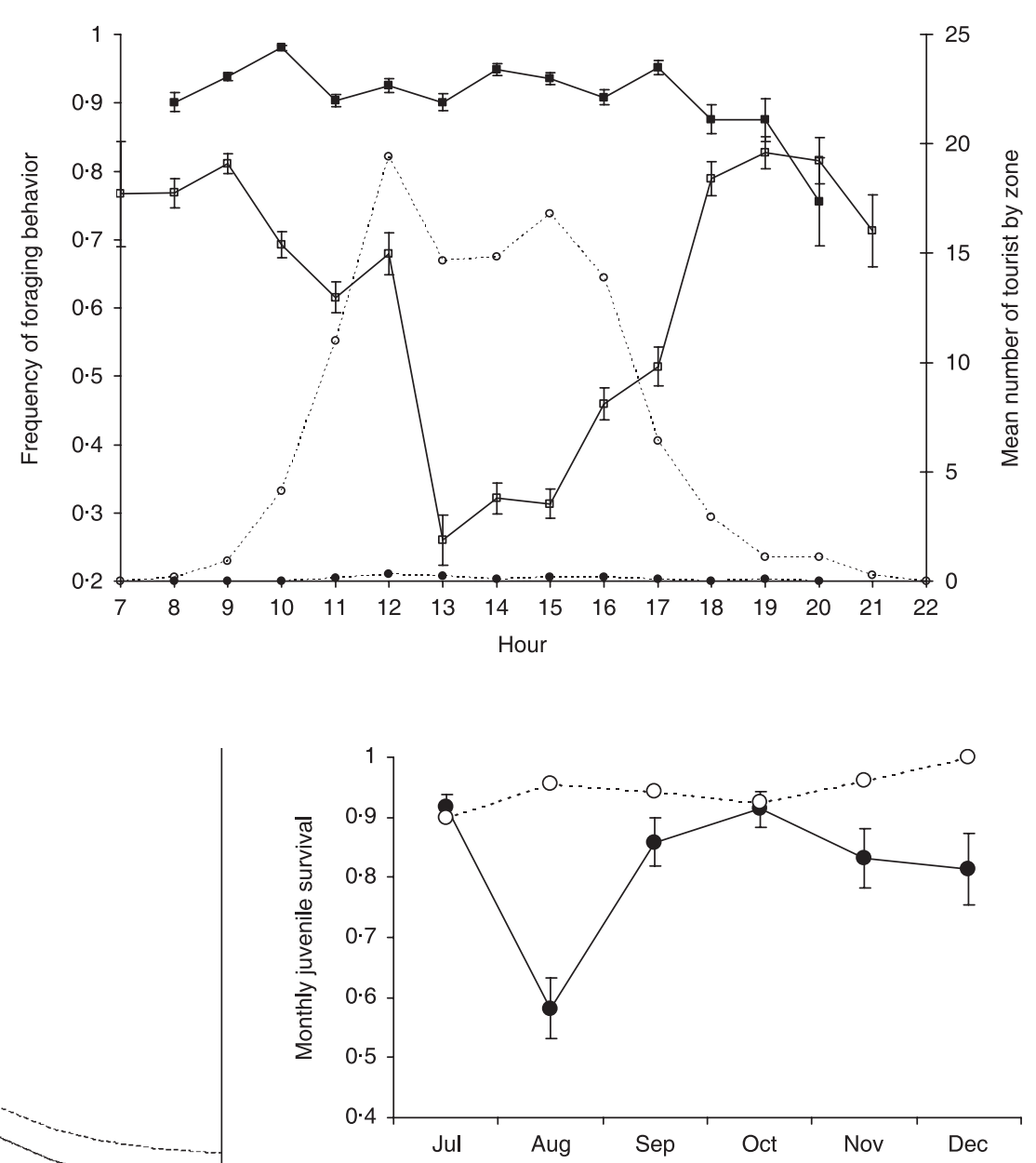

Fig. 3. Temporal changes in chough juvenile survival within a year Closed circles: average survival rates in Ouessant (1998-2005, 122 fledglings), errors bars represent standard errors; open circles: Islay (1983-1985; $n=173$, Bignal et al. 1987).

due to the difference between survival in August and other months (58 vs. 81-94\%, Fig. 3 and Supporting Information, Table S3.3). Monthly juvenile survival was constant across years for all months except for August: this significant yearly variation seemed to be attributable to variation in August visitor number (higher survival with lower visitor numbers, Fig. 3, ANODEV, $F_{1,4}=78.87 ; \quad P<0.001 ; \beta=-0.44 \pm 0 \cdot 09$; Fig. 4) but also to variation in August rainfall (higher survival with lower rainfall, ANODEv, $F_{1,4}=13 \cdot 70 ; P=0 \cdot 01$; $\beta=-0 \cdot 02 \pm 0 \cdot 01)$. The effect of August rainfall on survival was nevertheless negligible compared to that of visitor number in August ( $\beta=-0.02$ vs. $-0 \cdot 44$, respectively). In contrast, the correlations between juvenile survival in August and breeding success, temperature or number of sunny days were not significant (ANODEV, $F_{1,4}=1 \cdot 48 ; P=0 \cdot 28 ; F_{1,4}=$ $1.99 ; P=0.22$; and $F_{1,4}=0.53 ; P=0.50$, respectively). Note that we detected no significant correlation between visitor numbers and weather (rainfall and visitor number: $F_{1,6}=0 \cdot 87$; $P=0.39$; temperature and visitor number: $F_{1,6}=0.004 ; P=$ $0 \cdot 95$; sunshine duration and visitor number: $F_{1,6}=1 \cdot 07 ; P=$ $0 \cdot 34)$.

Juvenile survival, estimated from fledging data collected from June to December varied across months, with most variation 


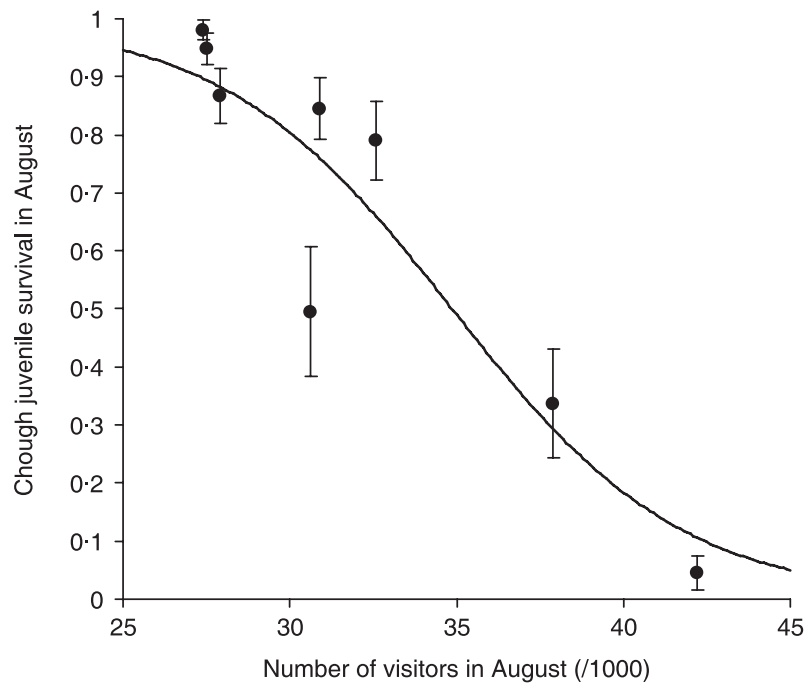

Fig. 4. Relationship between August juvenile survival and the number of visitors on Ouessant in August.

\section{CHOUGH POPULATION VIABILITY}

In the absence of regulation and inter-annual variation in demographic parameters, the deterministic matrix model predicted a slight annual increase of the population (asymptotic growth rate $\lambda=1.0189$ ) and a geometric increase in population size (Fig. 5). Moreover, the sensitivity of $\lambda$ to adult survival rates was high (elasticity $=0 \cdot 82$ ), while variation in juvenile survival had a weak influence on the deterministic growth rate $\lambda$ (elasticity $=0 \cdot 17$ ).

In contrast to the deterministic model, the IBM model included population regulation, which yielded densitydependent behaviours in some cases (Supporting Information, Fig. S3.4). However, density-dependence never affected the main prediction of the model, that is, a strong impact of tourism on short-term population dynamics and viability, which suggests an appreciable influence of reduced juvenile survival on chough population growth rate. We examined four scenarios regarding the future change in the number of visitors, $x_{\mathrm{t}}$ (Fig. 5). With no deterministic increase in visitor number, the IBM model predicted relatively stable chough population sizes $(56.07 \pm 0.06$ individuals and 36.51 \pm 0.03 breeders for Scenario A; 47.63 \pm 0.49 individuals and $30.99 \pm 0.56$ breeders for Scenario B), but with stochastic variation the IBM model predicted much higher extinction probabilities ( $1 \%$ vs. $10 \%$ over 50 years in Scenarios A and B, respectively). When the current rate of increase in the number of visitors was considered (Scenarios C and D), the chough population size dropped rapidly, and extinction was almost unavoidable within 50 years. Scenario C (deterministic temporal increase in visitor number without stochastic variation) led to the lowest viability $(100 \%$ extinction after 49 years). The differences among scenarios were little modified by changes in adult survival or nest limitation (Supporting Information, Fig. S3.4).
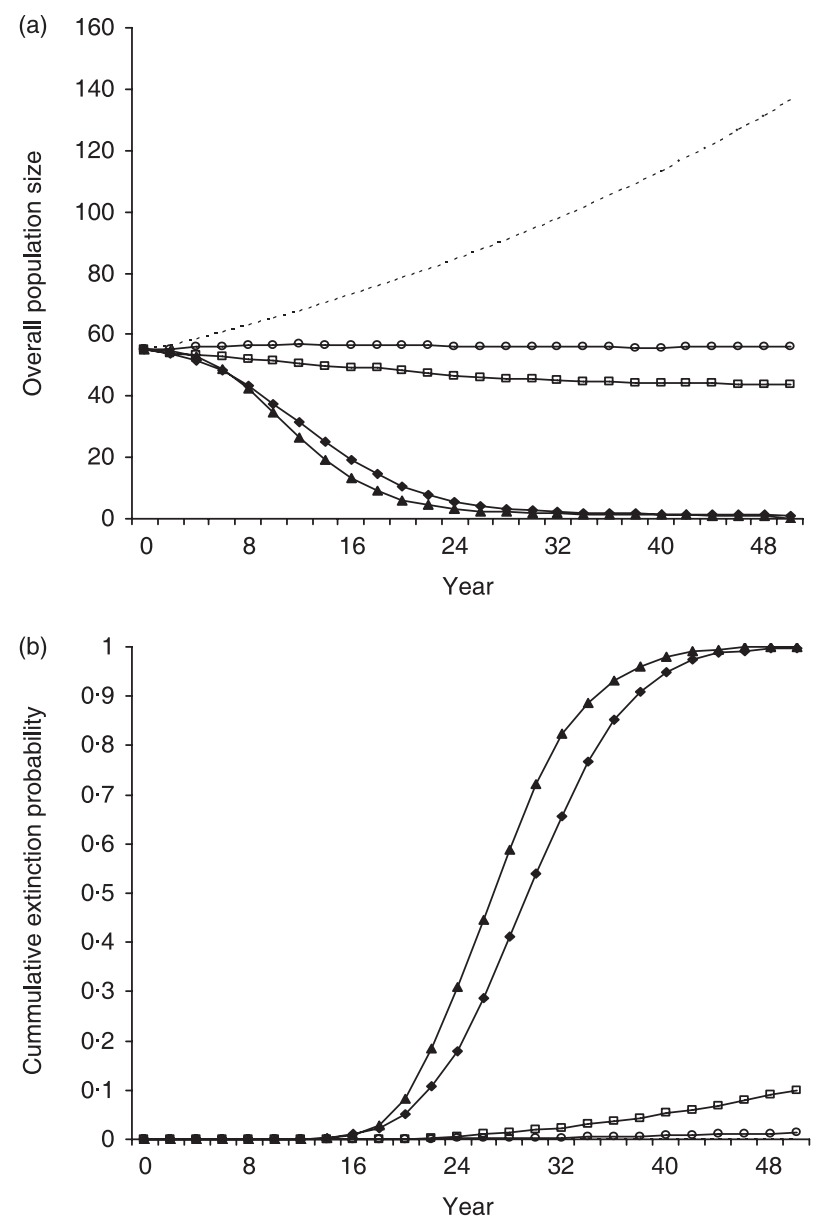

Fig. 5. Temporal variation in mean population size (a) and extinction probability (b) under the deterministic matrix (dashed line) and individual-based (solid lines) models. Parameter values are provided in Table 1. Standard errors were too small to be plotted. Open circles: constant number of visitors (Scenario A); open squares: stochastic variation in visitor number (Scenario B); solid triangles: deterministic increase in visitor number (Scenario C); solid diamonds: deterministic increase and stochastic variation in visitor number (Scenario D).

\section{Discussion}

Our results indicate that the presence of visitors on Ouessant Island resulted in a severe decrease in the area available for foraging in choughs and a reduction in the time allocated to foraging. This translates into reduced summer juvenile survival and, we predict, reduced population viability. Below, we discuss the relationship between the number of visitors and population viability, and derive recommendations to facilitate the coexistence of tourism and viable population of choughs.

\section{REDUCED RESOURCE AVAILABILITY RESULTED IN REDUCED JUVENILE SURVIVAL}

Visitor-induced disturbance is of conservation concern only if it actually affects population viability. This seemed to be the 
case in the chough population of Ouessant, although the observed disturbance (birds fly off during their foraging time) may appear minor at first. First, the survival of juveniles in their first year was much lower in Ouessant $(32 \%)$ than in a comparable island hosting choughs (Islay, UK, estimated juvenile survival $=71 \%$ in Bignal et al. $1987 ; 42 \%$ in Reid et al. 2003a,b), despite large differences in survival estimates in the latter. Secondly, survival rates in Ouessant varied from month to month, and were lowest (58\%) in August. This again contrasted with the situation on Islay, where monthly juvenile survival rates were above $90 \%$ all year round. August mortality accounted for half of the total observed mortality on Ouessant between July and January. Most authors agree that the postfledging period, when juvenile choughs become independent, is often critical for their survival (Holyoak 1971; Bullock, Drewett \& Mickleburgh 1983; Robert 1985). However, the low juvenile survival in August is not merely the result of birds reaching nutritional independence, because in Ouessant more than half of yearlings become independent in September or July (Kerbiriou et al. 2006a,b), two months when high survival rates were recorded. Thirdly, the large difference in survival rates between August and other months (June, July, September and October) was not explained by changes in prey assemblages (see Kerbiriou \& Julliard 2007), prey biomass, day length or weather conditions (temperature and rainfall), but was strongly correlated with the number of visitors on the island.

The most obvious physiological mechanism causing the observed excess juvenile mortality is severe undernourishment, due to the reduction in feeding time budget. On Ouessant, three ringed juveniles were found freshly dead in summer without any external parasite or wound. All three exhibited abnormally low weight (162 g, $184 \mathrm{~g}$ and $180 \mathrm{~g}$ vs. 261-295 g for healthy ringed fledglings) and had suffered severe weight loss since they were ringed 1 or 1 months earlier $(-53 \mathrm{~g},-94 \mathrm{~g}$ and $-135 \mathrm{~g}$, respectively). In addition, undernourishment may have acted in synergy with a production of corticoids, often associated with human disturbance (see Sapolsky 1992), to reduce juvenile survival.

\section{REDUCED JUVENILE SURVIVAL AFFECTS POPULATION VIABILITY IN A LONG-LIVED SPECIES}

Age-structured models of long-lived species predict that variation in juvenile survival rates should have little effect on population growth rate compared to variation in adult survival rates (Caswell 1989). In the Ouessant chough population, a species whose demographic parameters indicate that it is relatively long-lived (Bullock et al. 1983; Roberts 1985; Reid et al. 2003a,b), reduced juvenile survival may be considered of little consequence for the population growth at first, as suggested by results from the deterministic model. However, long-term studies of long-lived species have also shown that demographic parameters of high elasticity, such as adult survival, were often the least variable parameters (Hatter \& Janz 1994; Gaillard, Festa-Bianchet \& Yoccoz 1998), in agreement with theoretical expectations (Stearns \& Kawecki 1994).
As a result, population dynamics can be much more influenced by demographic parameters with smaller elasticity but larger variability (Gaillard et al. 1998), such as juvenile survival or fecundity. This pattern has been reported in various populations of long-lived birds, as exemplified by the California spotted owls (Blakesley, Noon \& Shaw 2001) or the southern fulmar (Jenouvrier et al. 2005). We have no information regarding adult survival in the Ouessant population, but a long-term study on Islay showed that the contribution of between-year variation in first-year and second-year survival to the total variance in the population growth rate was similar to that of adult survival (Reid et al. 2004).

The Ouessant breeding population has been fairly stable in the last 50 years (10 to 13 pairs), but we observed a strong decrease in the number of non-breeders, from about 55 individuals in the 1970 s to only 15 currently. Agricultural changes are probably an important driver of this loss, but we believe visitor disturbance is also involved, via a reduction in juvenile survival that could lead to a point where the production of juveniles does not compensate adult mortality and where the population is likely to go extinct rapidly. This is supported by our simulations, predicting a relatively large number of non-breeders under scenarios with a low probability of extinction (Fig. 5; 19.6 and 16.6 non-breeders without or with stochastic variation, respectively), that is, when the number of visitors remains at its current level. Under this model, non-breeders were expected to account for $35 \%$ of the population, of which $16 \%$ were old enough to reproduce $(>2$ years old). In contrast, under scenarios with quasi-certain extinction (deterministic or stochastic increase in visitor numbers), non-breeders accounted for $11 \%$ only of the population, and were all $\leq 2$ years old.

\section{PERSPECTIVES FOR THE CONSERVATION OF CHOUGHS IN OUESSANT AND OTHER PROTECTED AREAS}

Our study suggests that tourism threatens the chough population of Ouessant to the point where the short-term viability is endangered. This threat from visitors must be taken into consideration because the population of Ouessant is one of the core populations in western France, despite its small size and isolation. Several simple management actions could be taken to improve access to feeding areas for the choughs. First, footpaths could be redrawn to preserve feeding areas from visitor disturbance. However, given the chough flush distance and the coastal location of chough feeding sites, paths would always have to be located $150 \mathrm{~m}$ away from the coastline, which would obviously be detrimental for visitors to the spectacular coastline and has little chance of being accepted by Park managers and Ouessant residents. Secondly, large sections of the coastline (26 ha of short grassland, i.e. the area used by the chough population at a given time) could be closed to tourist access throughout August. Given the current distribution of the chough feeding habitat, this would result in a minimum of $3 \mathrm{~km}$ of coastline closed to visitor access, i.e. $8 \%$ of Ouessant coastline. Finally, it would be possible to 
create 26 ha of short grassland, through grazing control, in inland areas, which are not attractive to visitors. A preliminary test (mowing of small inland areas in spring) showed that choughs do use these new foraging areas, although they are not adjacent to their former foraging sites, and suggested that this may result higher fledging success.

Conservation policies need not rely on complete separation of choughs and visitors, and there is hope that space can be shared between protected birds and visitors. Obviously, the latter should be informed about conservation issues and advised to avoid foraging flocks of choughs. In addition, the observed response of choughs to increasing visitor number (Fig. 3) indicates that birds could spend $92 \%$ of their time foraging (i.e. the time they spend without disturbance) if the number of visitors within $3 \mathrm{~km}$ of the coastline does not exceed 0.7 per hour. In addition, considering that the chough population requires 26 ha of short grassland at all times and that for a given number of visitors, the proportion of visitors within each zone does not change, we estimate that the number of tourists should not exceed 16500 in August (i.e. half the current number). However, this solution is probably not economically sustainable because tourism is the main source of income on Ouessant. A realistic approach would be to combine different strategies defined with respect to local situation (reroute paths away from priority feeding areas, create feeding habitats on areas with low tourist interest, etc.). At the island level, an education programme to increase visitor awareness of the detrimental effects of wildlife disturbance must be launched.

Despite Caughley's (1994) recommendation to use a mixing of the two paradigms of conservation biology, the decliningpopulation and the small-population paradigm, few studies have so far quantified the link between ultimate factors of species decline, stochastic processes and extinction risk for particular species or populations. By demonstrating how tourism pressure is related to both individual response and population dynamics in an endangered bird species, we hope that the present study is a step in the right direction.

\section{Acknowledgements}

Christian Kerbiriou thanks the 'Centre d'Etude du Milieu d'Ouessant' for funding between 1995 and 2005. We are grateful to Jacques Nisser for his help to work out ringing techniques; we thank Aurélien Audevard and Vincent Le Pennec for their important contribution to resighting of marked choughs, Emmanuel Girauded for help with GIS, Grégoire Lois and Hélène Pouliquen for an earlier reading of our manuscript and MétéoFrance for providing meteorological data. Finally, we wish to thank Jeremy Wilson, Paola Laiolo and Durwyn Liley for their constructive comments.

\section{References}

Beale, C.M. \& Monaghan, P. (2004) Behavioural responses to human disturbance: a matter choice? Animal Behavior, 68, 1065-1069.

Belanger, L. \& Bedard, J. (1989) Responses of staging greater snow geese to human disturbance. Journal of Wildlife Management, 53, 713-719.

Bignal, E., Monaghan, P., Benn, S., Bignal, S., Still, E. \& Thompson, P.M. (1987) Breeding success and post-fledging survival in the Chough (Pyrrhocorax pyrrhocorax). Bird Study, 34, 39-42.

Blakesley, J.A., Noon, B.R. \& Shaw, D.W.H. (2001) Demography of the California spotted owl in northeastern California. Condor, 103, 667668.
Blanco, G., Tella, J.L. \& Torre, I. (1998) Traditional farming and key foraging habitats for chough Pyrrhocorax pyrrhocorax conservation in a Spanish pseudo-steppe landscape. Journal of Applied Ecology, 35, 232-239.

Boo, E. (1990) Ecotourism: The Potentials and Pitfalls, Vol. 2 Country Case Studies. World Wildlife Fund, Washington, D.C.

Buckley, R.C. (2003) Ecological indicators of tourist impacts in parks. Journal of Ecotourism, 2, 54-66.

Bullock, I.D., Drewett, D.R. \& Mickleburgh, S.P. (1983) The chough in Britain and Ireland. British Birds, 76, 377-401.

Burfield, I. \& Bommel, F.V. (2004) Birds in Europe: Population Estimate, Trends and Conservation Status. BirdLife International Series no., Cambridge U.K.

Carney, K.M. \& Sydeman, W.J. (1999) A review of human disturbance effects on nestling colonial waterbirds. Waterbirds, 22, 68-79.

Caswell, H. (1989) Matrix Population Models: Construction, Analysis, and Interpretation. Sinauer Associates, Sunderland, MA.

Caughley, G. (1994) Directions in conservation biology. Journal of Animal Ecology, 63, 215-244.

Duchesne, M., Cote, S.D. \& Barette, C. (2000) Responses of woodland caribou to winter ecotourism in the Charlevoix Biosphere Reserve, Canada. Biological Conservation, 96, 311-317.

Ferriere, R., Sarrazin, F., Legendre, S. \& Baron, J-P. (1996) Matrix population models applied to viability analysis and conservation: theory and practice using the ULM software. Acta Oecologia, 17, 629-656.

Gaillard, J.M., Festa-Bianchet, M. \& Yoccoz, N.G. (1998) Population dynamics of large herbivores: variable recruitment with constant adult survival. TREE, 13, 58-63.

Gill, J.A., Norris, K. \& Sutherland, W.J. (2001) Why behavioural responses may not reflect the population consequences of human disturbance. Biological Conservation, 97, 265-268

Hastie, T.J. \& Tibshirani, R.J. (1990) Generalized Additive Models. Chapman and Hall, London.

Hatter, I.W. \& Janz, D.W. (1994) Apparent demographic changes in blacktailed deer associated with wolf control on northern Vancouver Island. Canadian Journal of Zoology, 72, 1556-1572.

Hill, D., Hockin, D., Price, D., Tucker, G., Morris, R. \& Treweek, J. (1997) Bird disturbance: improving the quality and utility of disturbance research. Journal of Applied Ecology, 34, 275-288.

Holm, T.E. \& Laursen, K. (2009) Experimental disturbance by walkers affects behaviour and territory density of nesting black-tailed Godwits Limosa limosa. Ibis, 151, 77-87.

Holyoak, D. (1971) Movements and mortality of Corvidae. Bird Study, 18, 97-106.

Hulbert, I.A.R. (1990) The response of ruddy shelduck Tadorna ferruginea to tourist activity in the Royal Chitwan National Park of Nepal. Biological Conservation, 52, 113-123.

Jenouvrier, S., Barbraud, C., Cazelles, B. \& Weimerskirch, H. (2005) Modelling population dynamics of seabirds: importance of the effects of climate fluctuations on breeding proportions. Oikos, 108, 511-522.

Kelly, C., Pickering, C.P. \& Buckley, R.C. (2002) Impacts of tourism on threatened plant taxa and communities in Australia. Environnemental Management and restoration, 4, 37-44.

Kerbiriou, C. (2001) Originalité de la population bretonne de crave à bec rouge dans un contexte européen. Alauda, 69, 25-42.

Kerbiriou, C. \& Julliard, R. (2007) Demographic consequences of prey availability and diet of red-billed chough (Pyrrhocorax pyrrhocorax). Bird Study, 54, 296-306.

Kerbiriou, C., Thomas, A., Floc'h, P., Beneat, Y., Floté, D., Gager, L. \& Champion, M. (2005) Recensement 2002 de la population bretonne de craves à bec rouge (Pyrrhocorax pyrrhocorax). Ornithos, 12, 113-122.

Kerbiriou, C., Gourmelon, F., Jiguet, F., Bioret, F., Le Viol, I. \& Julliard, R. (2006a) Linking territory quality and reproductive success in the chough (Pyrrhocorax pyrrhocorax): implications for conservation management of an endangered population. Ibis, 148, 352-364

Kerbiriou, C., Le Viol, I., Nisser, J., Audevard, A. \& Le Pennec, V. (2006b) Biologie de la reproduction du Crave à bec rouge (Pyrrhocorax pyrrhocorax) en Bretagne (France). Alauda, 74, 399-412.

Kerbiriou, C., Leviol, I., Jiguet, F. \& Julliard, R. (2008) The impact of human frequentation on coastal vegetation in a biosphere reserve Journal of Environmental Management, 88, 715-728.

King, J.M. \& Heinen, J.T. (2004) An assessment of the behaviors of overwintering manatees as influenced by interactions with tourists at two sites in central Florida. Biological Conservation, 117, 227-234.

Levrel, H., Kerbiriou, C., Couvet, D. \& Weber, J. (in press) OECD Pressurestate-response indicators for managing biodiversity: a realistic perspective for a French biosphere reserve. Biodiversity and Conservation [doi: 10.1007/ S10531-008-9507-0]. 
Liley, D. \& Sutherland, W.J. (2007) Predicting the population consequences of human disturbance for ringed plovers Charadrius hiaticula: a game theory approach. Ibis, 149, 82-94.

MacArthur, R.A., Geist, V. \& Johnston, R.H. (1982) Cardiac and behavioural responses of mountain sheep to human disturbance. Journal of Wildlife Management, 46, 351-358.

Mallord, J.W., Dolman, P.M., Brown, A.F. \& Sutherland, W.J. (2007) Linking recreational disturbance to population size in a ground-nesting passerine. Journal of Applied Ecology, 44, 185-195.

Nisbet, I.C.T. (2000) Disturbance, habituation, and management of waterbird colonies. Waterbirds, 23, 312-332.

Patthey, P., Wirthner, S., Signorell, N. \& Arlettaz, R. (2008) Impact of outdoor winter sports on the abundance of a key indicator species of alpine ecosystems. Journal of Applied Ecology, 45, 1704-1711.

Pollock, K.H., Bunck, C.M., Winterstein, S.R. \& Chen, C. (1995) A capturerecapture survival analysis model for radio-tagged animals. Journal of Applied Statistics, 22, 661-672.

Reid, J.M., Bignal, E.M., Bignal, S., McCracken, D.I. \& Monaghan, P. (2003a) Environmental variability, life-history covariation and cohort effects in the red-billed chough. Journal of Animal Ecology, 72, 36-46.

Reid, J.M., Bignal, E.M., Bignal, S., McCracken, D.I. \& Monaghan, P. (2003b) Age-specific reproductive performance in red-billed choughs Pyrrhocorax pyrrhocorax: patterns and processes in a natural population. Journal of Animal Ecology, 72, 765-776.

Reid, J.M., Bignal, E.M., Bignal, S., McCracken, D.I. \& Monaghan, P. (2004) Identifying the demographic determinants of population growth rate: a case study of red-billed choughs Pyrrhocorax pyrrhocorax. Journal of Animal Ecology, 73, 777-788.

Riddington, R., Hassall, M., Lane, S.J., Turner, P.A. \& Walters, R. (1996) The impact of disturbance on the behaviour and energy budgets of Brent geese Branta b. bernicla. Birds Study, 43, 269-279.

Roberts, P.J. (1985) The choughs of bardsey. British Birds, 78, 217-232.

Rodrigues, A.S.L., Andelman, S.J., Bakarr, M.I., Boitani, L., Brooks, T.M., Cowling, R.M., Fishpool, L.D.C., da Fonseca, G.A.B., Gaston, K.J., Hoffmann, M., Long, J.S., Marquet, P.A., Pilgrim, J.D., Pressey, R.L., Schipper, J., Sechrest, W., Stuart, S.N., Underhill, L.G., Waller, R.W., Watts, M.E.J. \& Yan, X. (2004) Effectiveness of the global protected area network in representing species diversity. Nature, 428(6983), 640643.

Saltz, D., Raanan, N., Manor, R., Motro, U. \& Mitrani, Y. (2002) Impact of human nuisance disturbance on vigilance and group size in two species of social ungulates. Society for Conservation Biology 16th Annual Meeting.
Durell Institute of Conservation and Ecology University of Kent at Canterbury and British Ecological Society.

Sapolsy, R. (1992) Neuroendocrinology of the stress response (eds J.B. Becker, S.M. Breedlove \& D. Crews), pp. 287-324. Behavioural Endocrinology. MIT Press, Cambridge MA, USA.

Stearns, S.C. \& Kawecki, T.J. (1994) Fitness sensitivity and the canalization of life-history traits. Evolution, 48, 1438-1450.

Thiel, D., Jenni-Eiermann, S., Braunisch, V., Palme, R. \& Jenni, L. (2008) Ski tourism affects habitat use and evokes a physiological stress response in capercaillie Tetrao urogallus: a new methodological approach. Journal of Applied Ecology, 45, 845-853.

White, G.C. \& Burnham, K.P. (1999) Program MARK: survival estimation from populations of marked animals. Bird Study, 46(suppl.), 120-139.

Zambrano, L., Vega, E., Herrera, L.G., Prado, E. \& Reynoso, V.H. (2007) A population matrix model and population viability analysis to predict the fate of endangered species in highly managed water systems. Animal Conservation, 10, 297-303.

Received 11 October 2008; accepted 17 February 2009

Handling Editor: Jeremy Wilson

\section{Supporting Information}

Additional Supporting Information may be found in the online version of this article:

Appendix S1. Location of the study area (Ouessant) and protection status levels (Fig. S1)

Appendix S2. Methodology details (one table and one figure)

Appendix S3. Results details (two tables and three figures)

Please note: Wiley-Blackwell are not responsible for the content or functionality of any supporting materials supplied by the authors. Any queries (other than missing material) should be directed to the corresponding author for the article. 